\title{
Interleukin-4 Induces CpG Site-Specific Demethylation of the Pendrin Promoter in Primary Human Bronchial Epithelial Cells
}

\author{
Giada Scantamburlo ${ }^{a}$ Simone Vanonia Silvia Dossena ${ }^{a}$ Selma M. Soyala \\ Emanuele Bernardinellia Davide Antonio Civello ${ }^{a}$ Wolfgang Patscha \\ Markus Paulmichl $^{b} \quad$ Charity Nofziger ${ }^{a}$ \\ Institute of Pharmacology and Toxicology, Paracelsus Medical University, Salzburg, ${ }^{b}$ Center for Health \\ \& Bioresources, Austrian Institute of Technology (AIT), Vienna, Austria
}

\section{Key Words}

Asthma $\cdot \mathrm{COPD} \cdot \mathrm{Lung} \cdot \mathrm{SLC} 26 \mathrm{~A} 4 \cdot \mathrm{STAT6}$

\begin{abstract}
Pendrin is upregulated in bronchial epithelial cells following IL-4 stimulation via binding of STAT6 to an $\mathrm{N}_{4}$ GAS motif. Basal CpG methylation of the pendrin promoter is cell-specific. We studied if a correlation exists between IL-4 sensitivity and the CPG methylation status of the pendrin promoter in human bronchial epithelial cell models. Methods: Real-time PCR and pyrosequencing were used to respectively quantify pendrin mRNA levels and methylation of pendrin promoter, with and without IL-4 stimulation, in healthy and diseased primary HBE cells, as well as NCI-H292 cells. Results: Increases in pendrin mRNA after IL-4 stimulation was more robust in NCI-H292 cells than in primary cells. The amount of gDNA methylated varied greatly between the cell types. In particular, CpG site 90 located near the $\mathrm{N}_{4}$ GAS motif was highly methylated in the primary cells. An additional CpG site (90bis), created by a SNP, was found only in the primary cells. IL-4 stimulation resulted in dramatic demethylation of CPG sites 90 and 90bis in the primary cells. Conclusions: IL-4 induces demethylation of specific CpG sites within the pendrin promoter. These epigenetic alterations are cell type specific, and may in part dictate pendrin mRNA transcription.
\end{abstract}

\section{Introduction}

Pendrin is an anion transporter exchanging chloride for iodide [1] or bicarbonate [2, 3]. The pendrin gene (SLC26A4) was identified for the first time in 1997 [4] by Everett et al. and was found to be mutated in patients with Pendred syndrome, an autosomal recessive disorder characterized by sensorineural deafness and a partial defect in iodide organification [5]. In the past decades, the role of pendrin has been well characterized in the thyroid gland [3], inner ear [6] and kidney [7, 8]. In these tissues, it is involved in iodide flux into the thyrocyte follicular lumen, maintenance of the $\mathrm{pH}$, ion composition and volume of the endolymph, and moreover body acid-base equilibrium, fluid homeostasis and blood pressure regulation.

Charity Nofziger, Ph.D.

or Markus Paulmichl, MD

KARGER
Institute of Pharmacology and Toxicology, Paracelsus Medical University

22 Strubergasse, Salzburg, A-5020; or Center for Health \& Bioresources, Austrian Institut of Technology (AIT) Muthgasse 11, 1190 Vienna (Austria)

E-Mail charity.nofziger@me.com / paulmichl@me.com 
Pendrin is also expressed, although at a minor level relative to the aforementioned tissues, in the placenta [9], lactating mammalian glands [10], testis [11], prostate [11], endometrium [12], platelets [13], and lung [14].

Although basal expression of pendrin in the lung bronchial epithelium is relatively low, it is upregulated in respiratory diseases, especially asthma and chronic obstructive pulmonary disease (COPD) [14-19]. In these disorders, pendrin is involved in inflammation and tissue remodelling by inducing the expression of a major mucus protein (MUC5AC) and regulating mucus secretion [16], as well as driving water reabsorption through chloride uptake to reduce the airway surface liquid (ASL) thickness [15]. Pendrin may also increase the anti-microbial action in this tissue by exchanging chloride with thiocyanate that, after being converted into hypothiocyanate in the ASL, elicits bactericidal and bacteriostatic activity [20]. It has been demonstrated in vitro that stimulation with interleukin-4 (IL-4) and IL-13 - two cytokines released during respiratory distresses [21] - results in increased pendrin mRNA transcription $[20,22]$. One of the main downstream effectors activated by IL-4 and IL-13 is the signal transducer and activator of transcription, STAT6. Activation of this transcription factor by phosphorylation has been shown to be directly responsible for increased pendrin mRNA expression stimulated by IL-4 through interaction with a functional $\mathrm{N}_{4}$ GAS motif present in the pendrin promoter [21,23].

A CpG island and shore, containing 91 individual $\mathrm{CpG}$ sites, is present within the 1850 nucleotides between the functional $\mathrm{N}_{4} \mathrm{GAS}$ motif and the transcription start site of the pendrin gene [24]. In the genomic sequence, cytosines followed by a guanine (CpG) are sites for DNA methylation, an epigenetic mechanism specifically referring to the transfer of a methyl group onto carbon atom 5 of cytosine. This covalent DNA modification mainly represses gene transcription through methyl-CpG-binding proteins that bind to methylated DNA in a non-sequence-specific manner [25-28]. Transcriptional repression is then achieved by interference with transcription factor binding and through association with histone deacetylases leading to chromatin remodelling [26, 29, 30].

We previously reported the existence of cell-specific methylation patterns for the pendrin promoter in the lung cancer cell line NCI-H292, derived from a lymph node metastasis of a pulmonary mucoepidermoid carcinoma, and the kidney cell line HEK-Blue, constitutively over-expressing STAT6 [24]. These results were particularly interesting for CpG sites 91 and 90 , located 2 and 81 nucleotides downstream of the $\mathrm{N}_{4}$ GAS motif, respectively. As we have shown in that study, HEK-Blue cell genomic DNA (gDNA) was $~ 60 \%$ more methylated at CpG site 91 and $\sim 70 \%$ more methylated at CpG site 90 compared to NCI-H292 gDNA [24]. In line with the general idea that hypermethylation hinders transcription, the greatest increase in pendrin mRNA expression after IL-4 treatment was observed in NCI-H292 cells.

These findings elicited the hypothesis that sensitivity to IL-4 may be dictated by the methylation status of the pendrin promoter, and highlighted CpG sites 91 and 90 as possible regulators of this interplay. The principal aim of this study was to evaluate the methylation status of the pendrin promoter in several bronchial cellular models and determine whether CpG methylation correlates with pendrin mRNA expression levels before and/or after treatment with IL-4. The cellular models used were NCI-H292 cells and primary human bronchial epithelial cells from a healthy subject (NHBE), and an asthmatic (DHBE-asthma) and COPD (DHBE-COPD) patient.

\section{Materials and Methods}

\section{Materials}

Human recombinant IL-4 was provided by InvivoGen (California, United States) and added to the cell culture media at a final concentration of $40 \mathrm{ng} / \mathrm{mL}$. NCI-H292 cells were obtained from ATCC (Virginia, United States). Primary cells (NHBE, DHBE-Asthma and DHBE-COPD) were obtained from Lonza (Basel, Switzerland). More detailed information about the individuals from which the primary cells were derived is listed in Table 1. All PCR and sequencing primers were obtained from Microsynth (Switzerland). 


\section{Cellular Physiology Cell Physiol Biochem 2017;41:1491-1502 \begin{tabular}{ll|l} 
and Biochemistry Published onlIne: IVIarch 24, 2017 & $\begin{array}{l}\text { (c) } 2017 \text { The Author(s). Published by S. Karger AG, Basel } \\
\text { www.karger.com/cpb }\end{array}$
\end{tabular}}

Table 1. Review of the information collected on the donors of the three primary cellular models. Data were provided by Lonza

\begin{tabular}{llll}
\hline & NHBE & DHBE-Asthma & DHBE-COPD \\
\hline Donor age & 58 & 45 & 49 \\
Donor gender & Female & Female & Female \\
Donor race & Caucasian & Caucasian & Caucasian \\
Smoking history? & no & yes & yes \\
Smoking duration (years) & - & 30 & 35 \\
\# pack/day & - & 2 & 1 \\
Medications (related to airway disease) & - & Albuterol & Unknown \\
Duration of disease & - & Unknown & 4 years \\
Additional comments & - & - & Emphysema \\
\hline
\end{tabular}

Cell culture

All cells were maintained at $37^{\circ} \mathrm{C}$ in a humidified incubator gassed with $5 \% \mathrm{CO}_{2}$. $\mathrm{NCI}-\mathrm{H} 292$ culture media consisted of RPMI-1640 base media (SIGMA, Missouri, United States) supplemented with 10\% v/v fetal bovine serum, 24.9mM D-glucose, $17.8 \mathrm{mM}$ sodium bicarbonate, $10 \mathrm{mM}$ HEPES, $1 \mathrm{mM}$ sodium pyruvate, $100 \mathrm{U} / \mathrm{mL}$ penicillin and $100 \mu \mathrm{g} / \mathrm{mL}$ streptomycin. NHBE and DHBE primary cell culture media consisted of bronchial epithelial cell basal medium supplemented with $0.1 \%$ hydrocortisone, human epidermal growth factor, epinephrine, transferrin, insulin, retinoic acid, triiodothyronine, gentamicin/amphotericin (GA) -1000 and $0.4 \%$ bovine pituitary extract (all from Lonza). Primary cells were subcultured at the recommended density of 10000 cell / $\mathrm{cm}^{2}$ while NCI-H292 cells were subcultured at a 1:10 dilution. Primary cells used for experiments ranged between 2 and 5 passages.

\section{gDNA and RNA extraction}

Cells were washed with $10 \mathrm{~mL} 1 \mathrm{X}$ phosphate $\underline{b} u f f e r$ saline solution (PBS) and lysed in $600 \mu \mathrm{L}$ RLT Plus Buffer (QIAGEN, Hilden, Germany), freshly supplemented with $\beta$-mercaptoethanol to a final concentration of $140 \mathrm{mM}$. Lysates were homogenized with QIAshredder columns (QIAGEN). gDNA and total RNA were then extracted and purified with the QIAcube (QIAGEN) using the AllPrepDNA, RNA, miRNA Universal kit (QIAGEN) according to the manufacturer's instructions. gDNA and total RNA were eluted in a final volume of $30 \mu \mathrm{L}$ nuclease-free water and quantified by spectrophotometry. RNA integrity was verified with the QIAxcel Advanced (QIAGEN) automated gel electrophoresis system (RNA screening cartridge, method CM-RNA).

\section{Bisulfite pyrosequencing}

gDNA (500ng) was bisulfite converted using the Epitect Fast Bisulfite Conversion Kit (QIAGEN) according to the manufacturer's instructions. Incubation at $60^{\circ} \mathrm{C}$ was increased from $10 \mathrm{~min}$ to $20 \mathrm{~min}$ to ensure complete bisulfite conversion. The concentration of bisulfite-converted gDNA was calculated using the QIAxpert spectrophotometer with an algorithm for single-stranded (ss)DNA. PCR reactions were prepared using the PyroMark PCR kit (QIAGEN) to amplify 20ng of bisulfite-converted gDNA. 50 $\mu \mathrm{L}$ PCR reactions consisted of $1 \mathrm{X}$ PyroMark PCR master mix, $1 \mathrm{X}$ CoralLoad, $0.2 \mu \mathrm{M}$ forward and reverse primer and $1.5 \mathrm{mM}, 1.75 \mathrm{mM}$ or $2 \mathrm{mM} \mathrm{Mg}^{2+}$, depending on the PCR reaction (see Table 2). Cycling parameters were as follows: denaturation at $95^{\circ} \mathrm{C}$ for $15 \mathrm{~min}$, followed by 50 cycles at $94^{\circ} \mathrm{C}$ for $30 \mathrm{sec}$, the appropriate annealing temperature (see Table 2) for $30 \mathrm{sec}$, and $72^{\circ} \mathrm{C}$ for $30 \mathrm{sec}$, followed by a final extension step at $72^{\circ} \mathrm{C}$ for $10 \mathrm{~min}$. The presence of the expected amplicons was verified using the QIAxcel Advanced automated gel electrophoresis system (DNA screening cartridge, method AL420). PCR amplicons were purified using the MinElute PCR purification kit (QIAGEN) according to the manufacturer's instructions, with supplementation of $10 \mu \mathrm{L} 3 \mathrm{M}$ sodium acetate for $\mathrm{pH}$ adjustment. Pyrosequencing reactions were performed on the PyroMark Q24 Instrument (QIAGEN) with 600ng purified PCR amplicon. The resulting pyrograms were analysed using the PyroMark Analysis Software with default settings. QIAGEN pyrosequencing assay design software (version 2.0) was used to design the PCR and sequencing primers reported in Table 2. The reverse PCR primers were biotinylated at the 5' end and purified by HPLC.

Amplification and Sanger sequencing of the pendrin promoter

PCR reactions $(50 \mu \mathrm{L})$ were prepared using JumpStart REDAccuTaq LA polymerase (SIGMA) and consisted of 1X AccuTaq LA Buffer, 0.5mM dNTPs, 5\% DMSO and 0.4 $\mu$ M forward (5' 
Scantamburlo et al.: IL-4 Demethylates the Human Pendrin Promoter

Table 2. PCR and sequencing primers for pendrin promoter methylation analyses. For each PCR reaction (Rxt), the optimized annealing temperature (Tm) and final magnesium concentration $\left(\mathrm{Mg}^{2+}\right)$ are reported. The CpG sites assesed by each PCR primer pair and sequencing primer are indicated

\begin{tabular}{|c|c|c|c|c|c|c|c|}
\hline Rxt & $\mathrm{Tm}$ & $\mathrm{Mg}^{2+}$ & Forward Primer 5'- 3' & Reverse (biotinylated) Primer 5'-3' & $\begin{array}{l}\text { Amplicon } \\
\text { (bps) }\end{array}$ & Sequencing Primer $5^{\prime}-3^{\prime}$ & $\begin{array}{l}\text { CpG site } \\
\text { analyzed }\end{array}$ \\
\hline $1 \mathrm{a}$ & $54^{\circ} \mathrm{C}$ & $2.5 \mathrm{mM}$ & TTATTGGGTGAAGTAAGTT & TAATCCACCTACCTTACA & 187 & GGTTTTTTGGGGAGG & 90 \\
\hline & & & & & & TGGGTAAGAAAGGGT & 87 \\
\hline 2 & $56^{\circ} \mathrm{C}$ & $1.75 \mathrm{mM}$ & GAGTTTAGTGGGTAAGAAAG & TACCACAAATACTCTCATACC & 237 & $\begin{array}{l}\text { GATTTGGATTGTGAAATAAAATAT } \\
\text { AGTGGTTAAAATTTGAGTAAA }\end{array}$ & $\begin{array}{l}86 \\
85\end{array}$ \\
\hline
\end{tabular}

AAAGGAGACACAGTGCTTGCCCTC 3') and reverse (5' GAAGGGTAAGCAACCATCTGTCAC 3') primers. Cycling parameters were as follows: denaturation at $94^{\circ} \mathrm{C}$ for $2 \mathrm{~min}$, followed by $35 \mathrm{cycles}$ at $94^{\circ} \mathrm{C}$ for $20 \mathrm{sec}, 59.6^{\circ} \mathrm{C}$ for $30 \mathrm{sec}$, and $68^{\circ} \mathrm{C}$ for $5.5 \mathrm{~min}$. The presence of the expected amplicon (4447bps) was verified on a $0.5 \%$ agarose gel. The PCR product was purified using the QIAquick PCR purification kit (QIAGEN) according to the manufacturer's instructions, with supplementation of $55 \mu \mathrm{L} 3 \mathrm{M}$ sodium acetate for $\mathrm{pH}$ adjustment. The entire amplicon was Sanger sequenced (Microsynth) in the forward and reverse orientations with 6 sequencing primers: 3 forward (5' TTGAAGATCTGTTGAAAGC 3'; 5' ATAGAAACCTGGCCATTG 3'; 5' TTTCTGAGACGCCGAGAGC 3') and 3 reverse (5' ACTGGACTACATGGAAATC 3'; 5' GTTTTCCGAGCAGCCTGTTC 3'; 5'CTCCGCCGCCCGCACCCCACTCTCGCCCGCTG 3').

\section{Reverse transcription and Real-Time PCR}

The dynamic range of the reverse transcription reaction was previously determined in house using human kidney RNA (Thermo Fisher Scientific, Massachusetts, United States) and the QuantiTect Reverse Transcription (RT) kit (QIAGEN). Experimental samples were reverse transcribed with the same kit. $1 \mu \mathrm{g}$ RNA was incubated with $1 \mathrm{X}$ gDNA wipe-out buffer in a $84 \mu \mathrm{L}$ reaction for $2 \mathrm{~min}$ at $42^{\circ} \mathrm{C}$, followed by $2 \mathrm{~min}$ cooling on ice. $41.5 \mu \mathrm{L}$ of the incubated mix were then added to $18 \mu \mathrm{L}+\mathrm{RT}$ and -RT reactions. Both these reactions contained 1X Quantiscript RT buffer and $3 \mu \mathrm{L}$ RT primer mix. $3 \mu \mathrm{L}$ Quantiscript reverse transcriptase was added to the + RT mix and $3 \mu \mathrm{L}$ RNAse-free water to -RT mix. The resulting $60 \mu \mathrm{L}$ reactions were incubated for $30 \mathrm{~min}$ at $42^{\circ} \mathrm{C}$, followed by $3 \mathrm{~min}$ at $95^{\circ} \mathrm{C}$ and cooling on ice. $10 \mu \mathrm{L}$ real-time PCR reactions were performed using hydrolysis probes in 384-well white plates on the LightCycler 480 II (Roche, Switzerland). Each reaction consisted of 1X Quantifast PCR mastermix (QIAGEN), 500nM/250nM $\beta$-ACTIN (ACTB) or SLC26A4 hydrolysis assays (Hs.PT.39a.22214847 and Hs.PT.58.27767752, respectively) (IDT, California, United States) and $4 \mu \mathrm{L}$ 1:10 diluted cDNA or -RT reaction. Cycling parameters were as follows: an initial denaturation at $95^{\circ} \mathrm{C}$ for $10 \mathrm{~min}$, followed by 40 cycles at $95^{\circ} \mathrm{C}$ for $10 \mathrm{sec}, 60^{\circ} \mathrm{C}$ for $30 \mathrm{sec}$ and $72^{\circ} \mathrm{C}$ for $1 \mathrm{sec}$. Relative gene expression values were determined using the comparative $\mathrm{Ct}$ method as described by Livak et al. [31]. No amplification was observed in the -RT reactions. The amplification efficiencies of the ACTB and SLC26A4 hydrolysis assays were experimentally determined with a 6-point log dilution curve using cDNA transcribed from $1 \mu \mathrm{g}$ human kidney RNA (Thermo Fisher Scientific) and human thyroid RNA (ClonTech, California, USA), respectively. The amplification efficiencies for both assays were between $95-100 \%$.

\section{Western Blotting}

Whole cell protein lysates were obtained by scraping cells in $1 \mathrm{X} \underline{\mathrm{S}} \mathrm{DS}$ solubilization $\underline{\mathrm{b} u f f e r}$ (SSB) containing 4\% SDS and 10\% glycerol in 0.5M Trizma base, pH 6.8. Just before use, 1X SSB was supplemented with Halt protease inhibitor cocktail (HPIC) (Thermo Fisher Scientific) and dithiothreitol to a final concentration of $1 \mathrm{X}$ and $1 \mathrm{mM}$, respectively. Protein concentrations were determined with the DC protein assay (Bio-Rad, California, United States). Protein extracts $(20 \mu \mathrm{g})$ were separated by electrophoresis with constant voltage $(120 \mathrm{~V})$ on $10 \%$ SDS-PAGE gels. Proteins were then transferred overnight at $4^{\circ} \mathrm{C}$ onto polyvinylidene fluoride (PVDF) membranes with constant amperage $(0.25 \mathrm{~mA})$. The membranes were blocked for $1 \mathrm{~h}$ at room temperature with agitation in 5\% nonfat dry milk diluted in wash buffer $(0.01 \%$ Tween-20 in Tris-buffered saline, pH7.6). Afterwards, PVDF membranes were incubated overnight with primary antibodies diluted in wash buffer containing $5 \%$ nonfat dry milk at $4^{\circ} \mathrm{C}$ with agitation. Three 5 min washes were then performed in wash buffer at room temperature with agitation, followed by $1 \mathrm{~h}$ incubation at room temperature with the secondary antibody diluted in wash buffer containing 5\% nonfat dry milk. 


\section{Cellular Physiology Cell Physiol Biochem 2017;41:1491-1502 \\ \begin{tabular}{l|l} 
and Biochemistry Published onlıne: March 24, 2017 & $\begin{array}{l}\text { (c) } 2017 \text { The Author(s). Published by S. Karger AG, Basel } \\
\text { www.karger.com/cpb }\end{array}$
\end{tabular}}

Scantamburlo et al.: IL-4 Demethylates the Human Pendrin Promoter

In the end, three additional 5 min incubations in wash buffer were performed. All incubation and wash steps with the secondary antibody were performed in the dark. Proteins were visualized using the ODYSSEY infrared imaging system (LICOR, Nebraska, United States). The rabbit polyclonal anti-phospho-STAT6 ${ }^{\mathrm{Y} 641}$ (\#9361, dilution 1:2000) and anti- $\beta$-actin (\#4967, dilution 1:2000) primary antibodies were from Cell Signaling (Massachusetts, United States). The anti-rabbit IRD-800-CW secondary antibody (\#926-32211, dilution 1:20000) was from LICOR. Densitometric analyses on Western blots were performed using ImageJ $(1.49 \mathrm{v})$ software.

PCR amplification bias calculation and correction

Methylation values were corrected by means of the cubic polynomial equation generated from the methylation levels observed for 100\%, 75\%, 50\%, 25\% and $0 \%$ methylation standards as described by Moskalev et al. [32]. PCR amplification bias (b) was assessed for 75\%, 50\% and 25\% methylation standards with the following equation: $b=\left[y^{*}(100-x)\right] /\left[x^{*}(100-y)\right]$, where $y$ is the observed methylation percentage, before or after correction, and $x$ is the expected methylation percentage [32].

Statistics

Statistical significance between two experimental groups was determined using the unpaired twotailed Student's t-test. For differences among three or more experimental groups, a one-way ANOVA followed by Tukey's post-hoc test was performed. Differences were considered statistically significant at $P$ values $<0.01$. Statistical analyses and graph generation were performed with GraphPad Prism 5.0 software (GraphPad, California, United States).

\section{Results}

Primary cells respond differently to IL-4 stimulation with respect to $\mathrm{NCI}-\mathrm{H} 292$ cells

NCI-H292 cells are a continuous cell line used as an in vitro model for the bronchial epithelium. Nevertheless, primary cells derived from fresh human tissue are likely more representative of the physiological conditions. Therefore, we decided to directly compare NCI-H292 cells with primary HBE cells. The primary HBE cells used in the present study originated from three different human donors: (i) a healthy donor (NHBE cells), (ii) an asthmatic patient (DHBE-Asthma cells) and (iii) a COPD patient (DHBE-COPD cells) (Table 1).

As previously described by Lee et al. [24], pendrin mRNA increases over time in NCI-H292 cells treated with IL-4. Accordingly, two hours after IL-4 (40 ng/ml) exposure, human pendrin mRNA expression in NCI-H292 cells increased significantly from $1.076 \pm$ $0.106(n=30)$ before IL-4 to $6.268 \pm 0.816$ after IL-4 $(n=30)$ (Fig. 1A). With prolonged IL-4 incubation, further increases in pendrin mRNA expression were observed (11.902 \pm 1.404 at $4 \mathrm{hrs}, 35.103 \pm 1.097$ at $24 \mathrm{hrs}$ and $54.751 \pm 3.219$ at $48 \mathrm{hrs}$; all $\mathrm{n}=30$ ).

Stimulating NHBE cells (from an individual not affected by asthma or COPD) also led to a significant increase in pendrin mRNA expression, but this increase was substantial only after $48 \mathrm{hrs}$ (from $1.049 \pm 0.059$ before IL-4 to $3.598 \pm 0.144$ after IL-4; $n=30$ ) (Fig. 1B) and still modest compared to that elicited in the NCI-H292 cells at the same time point (3.598 \pm .0789 in NHBE vs. $54.75 \pm 17.04 *$ in NCI-H292 cells after IL-4 for $48 \mathrm{hrs}$, where ${ }^{*} \mathrm{p}<0.01$ by Student's $t$-test; $\mathrm{n}=30$ each). The $48 \mathrm{hrs}$ IL-4 incubation time was chosen for the remainder of the experiments.

It has been postulated that pendrin may negatively alter the function of the bronchial epithelium during respiratory distresses [22]. In addition, since IL-4 is naturally released during respiratory diseases, we wondered if the basal level of pendrin mRNA expression and/or the responsiveness to IL-4 in terms of the amount of pendrin mRNA produced differs in normal versus diseased bronchial epithelial cells. Therefore, we analysed the amount of pendrin mRNA in primary HBE cells from a healthy volunteer (NHBE), an asthmatic patient (DHBE-Asthma), and a COPD patient (DHBE-COPD). 
Fig. 1. The response to IL-4 in terms of pendrin mRNA differs between NCI-H292 and NHBE cells. (A) NCI-H292 and (B) NHBE cells were treated with vehicle (water) or IL-4 (40 ng/ $\mathrm{mL}$ ) for $15 \mathrm{~min}, 2 \mathrm{hrs}, 4 \mathrm{hrs}$, $24 \mathrm{hrs}$ and $48 \mathrm{hrs}$. Pendrin (SLC26A4) mRNA expression was analysed with real-time PCR using -ACTIN (ACTB) as the housekeeping gene. The bars represent the average \pm SEM from three biological experiments containing ten technical replicates each, where ${ }^{*} \mathrm{p}<0.01$ compared to the respective vehicle treated control by the unpaired Student's t-test.

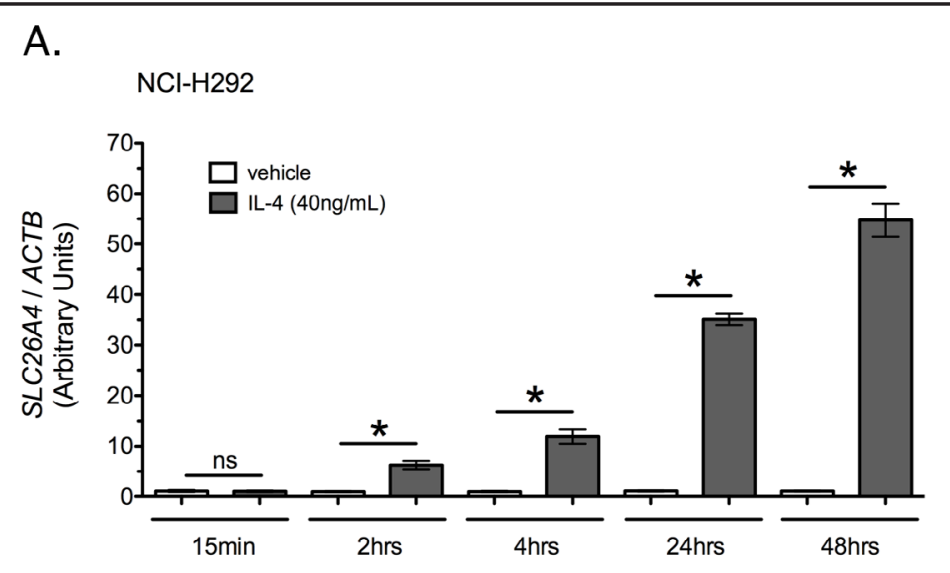

B.

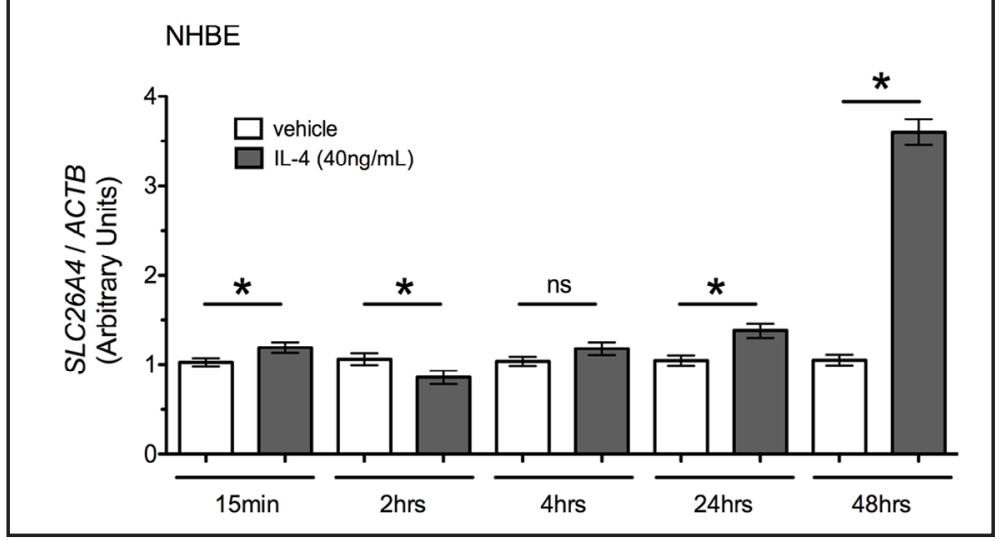

Fig. 2. The amount of pendrin mRNA induced by IL-4 varies in primary bronchial epithelial cell models. NHBE, DHBE-Asthma and DHBE-COPD cells were treated with vehicle (water) or IL-4 (40 ng/ $\mathrm{mL}$ ) for 48 hrs. Pendrin (SLC26A4) mRNA expression was analysed with real-time PCR using $\beta$-ACTIN $(A C T B)$ as the housekeeping gene. The bars represent the average \pm SEM from three biological experiments containing ten technical replicates each, where ${ }^{*} \mathrm{p}<0.01$ by the unpaired Student's $t$-test and ${ }^{s} \mathrm{p}<0.01$ by a one-way ANOVA followed by Tukey's post-hoc test. ns = non significant.

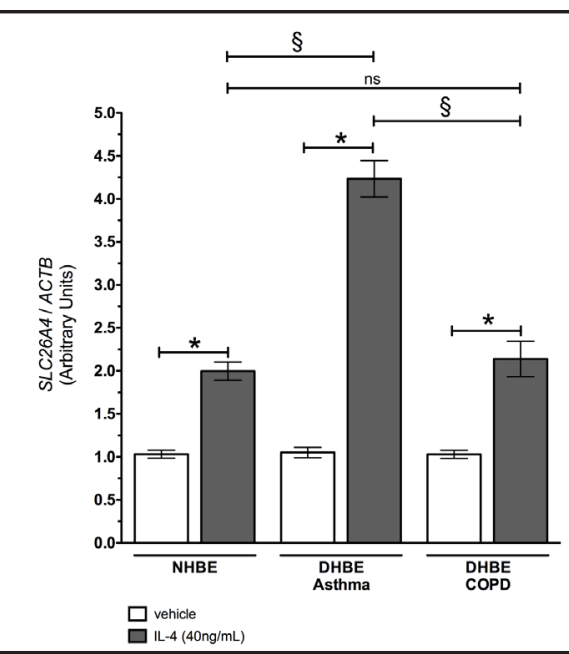

Pendrin mRNA expression in un-stimulated cells was low in all the cell types and did not differ statistically between them (data not shown). On the other hand, stimulation for 48 hrs with IL-4 resulted in a statistically significant increase in pendrin mRNA levels between primary HBE cells (Fig. 2). The DHBE-Asthma cells responded to IL-4 with the greatest increase in pendrin mRNA, and the amount of pendrin mRNA produced did not statistically differ in the other two primary cells types.

The apparent differences in pendrin mRNA levels induced by IL- 4 in the different cell types could be due to the amount of STAT6 that is activated following IL-4 exposure. We therefore analysed the expression of active (phosphorylated) STAT6 (STAT6-P) in each of the 
Fig. 3. Stimulation with IL-4 activates the same amount of STAT6 in primary bronchial epithelial cell models. NHBE, DHBE-Asthma, DHBE-COPD and NCI-H292 cells were treated with vehicle (water) or IL-4 (40 ng/mL) for 48 hrs. (A) STAT6 phosphorylation was analysed with Western Blot on whole cell lysates using $\beta$-ACTIN (ACTB) as the loading control. The molecular weight (kDa) markers are shown on the very left of the image. Bands corresponding to the predicted size of STAT6-P $(\sim 110 \mathrm{kDa})$ and ACTB $(\sim 42 \mathrm{kDa})$ were detected. The image is representative of three biological experiments. (B) Densitometric analysis of the Western blots. The amount of STAT6-P was normalized to that of ACTB in the IL-4 treated cells. The bars represent the average \pm SEM from three separate experiments. No statistically significant differences were detected by a one-way ANOVA followed by Tukey's post-hoc test for a $\mathrm{p}<0.01$.

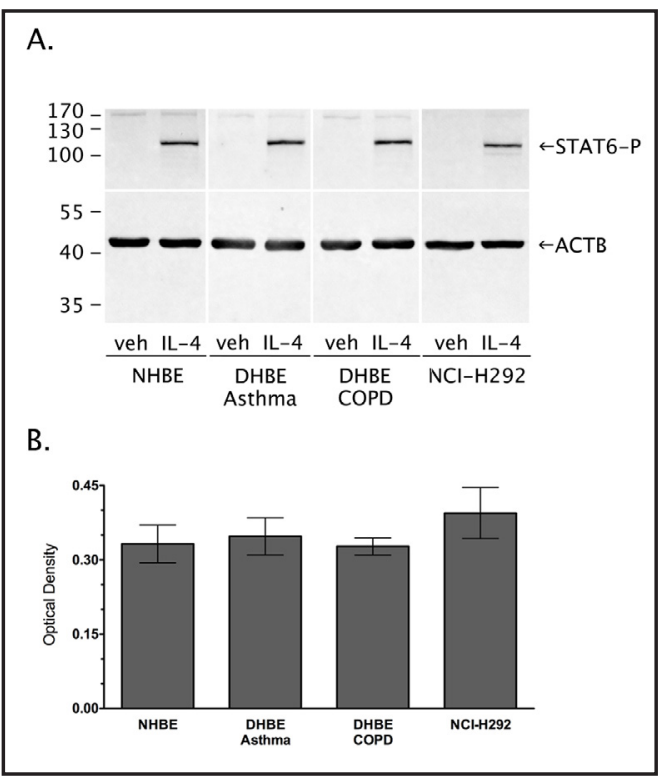

Fig. 4. IL-4 demethylates pendrin promoter $\mathrm{CpG}$ sites in primary bronchial epithelial cell models. Percentage of gDNA methylated at different $\mathrm{CpG}$ sites within the pendrin promoter from NHBE, DHBE-Asthma, DHBE-COPD and NCI-H292 cells treated with water (vehicle, open squares) or IL-4 ( $40 \mathrm{ng} / \mathrm{mL}$ ) (closed circles) for 48 hours. Six CpG sites (91, 90, 89, 87,86 and 85 ) were analysed with pyrosequencing on the forward gDNA strand. CpG site 88 was not included in the analyses due to de-

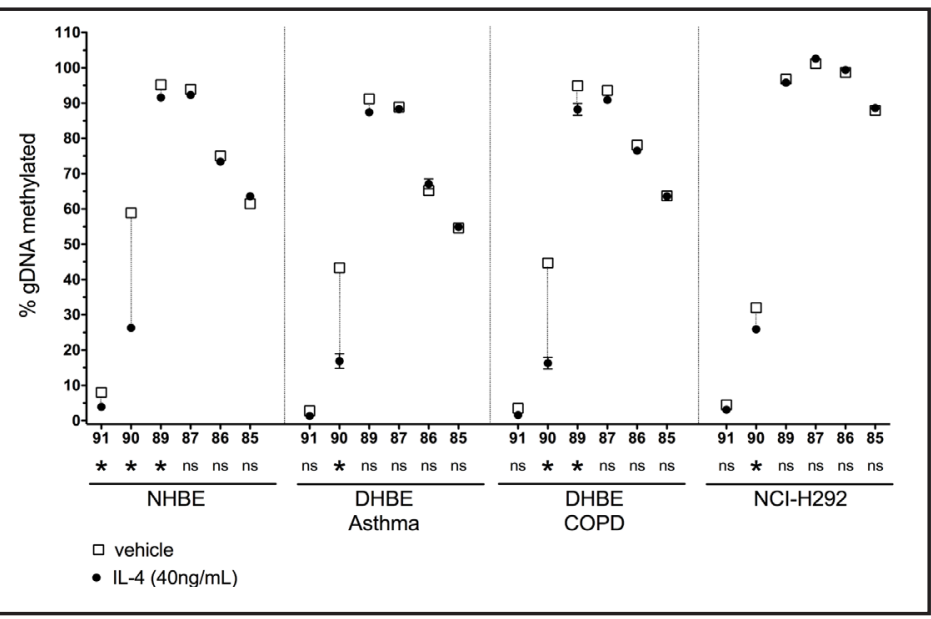
sign constraints. Symbols represent the average \pm SEM from three biological experiments containing three technical replicates each, where ${ }^{*} \mathrm{p}<0.01$ compared to the respective vehicle by the unpaired Student's $t$-test.

cell types. As shown in Fig. 3, phosphorylation of STAT6 was only observed in IL-4 treated cells, and densitometric analyses demonstrated that the amount of STAT6-P was similar in all of the four cellular models.

\section{IL-4 induces site and cell-specific demethylation}

Since epigenetic regulation may greatly influence transcription, we hypothesized that the differential response to IL-4 between the cell types might be due to variability of CpG site methylation within the pendrin promoter. We chose to focus on six CpG sites $(91,90$, $89,87,86$ and 85 ) within the pendrin promoter due to their proximity to the $\mathrm{N}_{4}$ GAS motif that is essential for the response to IL-4 $[21,23]$. The basal and IL-4 stimulated methylation patterns for these CpG sites in all four cell types are shown in Fig. 4. Some generalizations regarding the observed methylation patterns can be made: i) only a very small percentage of the gDNA at CpG site 91 was methylated (not more than 8\% in each cell type) and ii) more than $50 \%$ of the gDNA at CpG sites 89, 87, 86 and 85 was methylated in all cellular models. On the other hand, the basal methylation patterns at some CpG sites in the primary HBE cells were significantly different with respect to the NCI-H292 cells. In particular, the total 
Fig. 5. The primary bronchial epithelial cell models harbour an additional $\mathrm{CpG}$ site created by a SNP that is also demethylated following IL-4 exposure. (A) Schematic representation of the human pendrin promoter region. The $\mathrm{N}_{4}$ GAS motif is located at g.-1812 through g.-1803 and CpG sites 91, 90bis and 90 are located 2 nucleotides, 55 nucleotides and 81 nucleotides downstream, respectively (GenBank Accession number AC078937.1). The presence of g. $1747 \mathrm{~A}>\mathrm{C}$ (rs2712228) creates an additional CpG site (90bis). (B) IL-4 demethylates pendrin promoter CpG site 90bis in primary bronchial epithelial cell models. The percentage of gDNA methylated at $\mathrm{CpG}$ site 90 bis within the pendrin promoter from NHBE, DHBE-
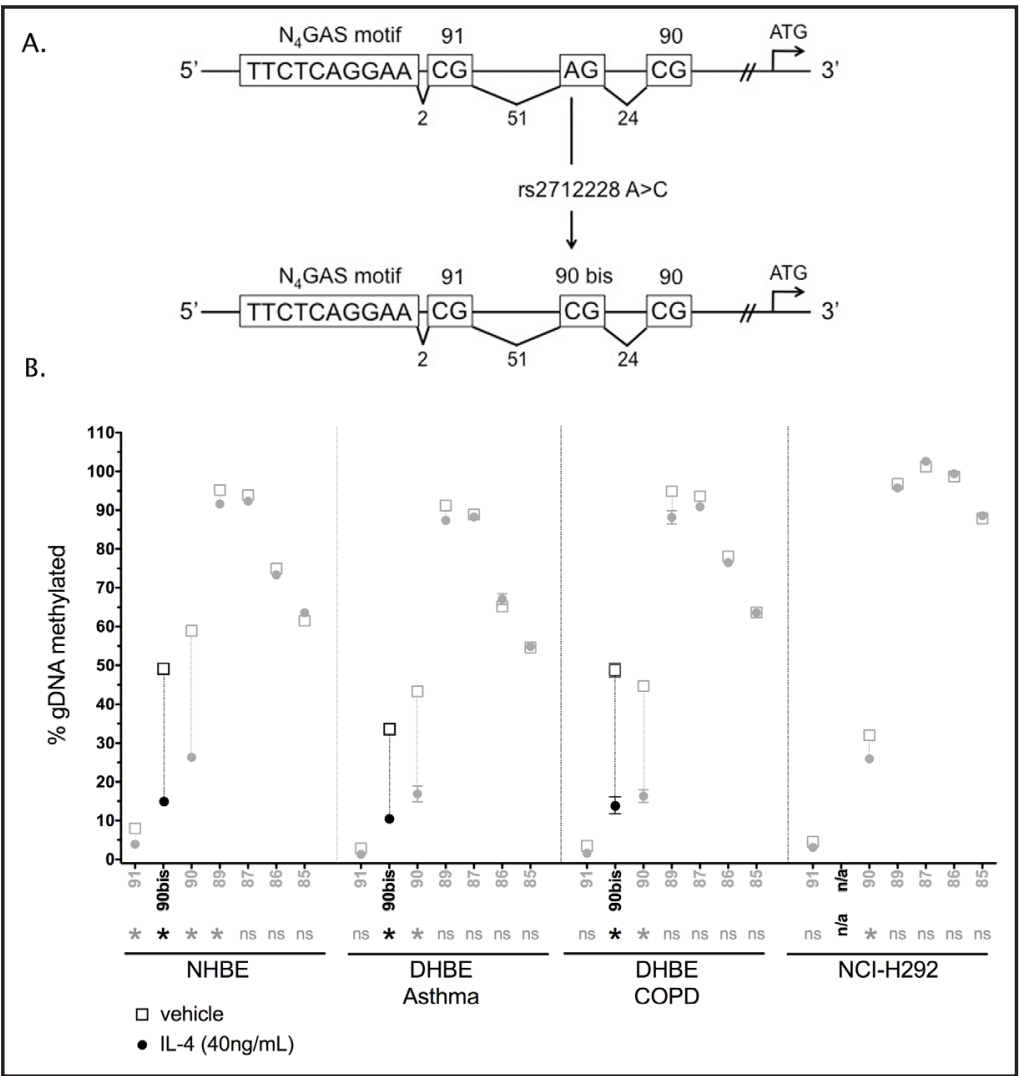
Asthma, and DHBE-COPD cells treated with water (vehicle, open squares) or IL-4 $(40 \mathrm{ng} / \mathrm{mL}$ ) (closed circles) for 48 hours is shown. The data (greyed out) from Fig. 4 were included with the data obtained for 90 bis. The methylation analyses were performed on the forward gDNA strand. CpG site 88 was not included in the analyses due to design constraints. Symbols represent the average \pm SEM from three biological experiments containing three technical replicates each, where * $\mathrm{p}<0.01$ compared to the respective vehicle by the unpaired Student's t-test.

amount of gDNA methylated at CpG site 90 was higher in the primary HBE cells with respect to NCI-H292 cells $(58.9 \pm 0.47$ in NHBE vs. $43.3 \pm 0.46$ in DHBE-Asthma vs. $44.7 \pm 0.75$ in DHBE COPD vs. $32.0 \pm 0.35 *$ in NCI-H292 cells where * $<<0.01$ by a one-way ANOVA followed by Tukey's post-hoc test; $n=9$ ), and the total amount of gDNA methylated at CpG sites 86 and 85 was lower in the primary HBE cells compared to the NCI-H292 continuous cell line. Interestingly, the methylation pattern after IL-4 stimulation was significantly altered, especially in the primary HBE cells. In particular, IL-4 significantly reduced the amount of gDNA methylated at CpG site 90 by more than $30 \%$ only in the primary cell types. The same site in the NCI-H292 cells was also significantly demethylated, but nevertheless only by $6 \%$.

IL-4 induces demethylation of a new CPG site generated in the pendrin promoter by a single nucleotide polymorphism

Genomic DNA is subject to sequence variations manifested as deletions, insertions or single nucleotide polymorphisms (SNPs). Depending on the nature of these SNPs, new CpG sites may be created or current CpG sites may be deleted. Indeed, several SNPs that could alter the number of CpG sites in the human pendrin promoter are known [24]. Since the four cellular models used in the present study were isolated from distinct individuals, we sequenced the pendrin promoter in each of them. Indeed, a new CpG site located between CpG sites 91 and 90 was generated by the SNP g.-1747A $>C$ (rs2712228) only in the three primary HBE cellular models (Fig. 5A). We named this CpG site 90bis, and it was found in 
homozygosity in the NHBE and DHBE-Asthma cells, and in heterozygosity in the DHBE-COPD cells. The allele frequency for this SNP in the NCBI dbSNP database is $51.9 \%$ in East Asians, 94.5\% in Africans and 32.7\% in Europeans.

In order to determine the methylation status of CpG site 90bis, a new pyrosequencing assay was designed (see Table 2), corrected for PCR amplification bias and used to analyse the same cell samples from which the data shown in Fig. 2 and 4 were generated. As shown in Fig. 5B, the amount of gDNA methylated at CpG site 90 bis was similar between the NHBE and DHBE-COPD cells in the basal state, but the amount of gDNA methylated at this CpG site was significantly lower in the DHBE-Asthma cells $(49.2 \pm 1.15$ in NHBE vs. $33.7 \pm 0.91 *$ in DHBE-Asthma vs. $48.8 \pm 1.72$ in DHBE-COPD where * $<0.01$ by a one-way ANOVA followed by Tukey's post-hoc test; $\mathrm{n}=9$ ). Intriguingly, treatment with IL-4 resulted in a significant reduction in the amount of gDNA methylated at this site in all three primary HBE models, similarly to that observed at CpG site 90 .

\section{Discussion}

Pendrin expression is increased in pathological respiratory conditions, including but not limited to asthma and COPD, and contributes to inflammation and mucus production [1419]. This upregulation is induced by phosphorylated STAT6, a transcription factor activated by IL-4, which recognises and binds to a functional $\mathrm{N}_{4}$ GAS motif present in the pendrin promoter [21, 23]. Several CpG sites, hotspots for DNA methylation, are located between the binding motif for STAT6 and the transcription start site of the pendrin gene. One aim of this study was to investigate if the methylation status of the human pendrin promoter is linked to the expression levels of pendrin mRNA before and/or after IL-4 exposure.

The current results showed a differential increase in pendrin mRNA between NCI-H292, NHBE, DHBE-Asthma and DHBE-COPD cells in response to IL-4. In particular, pendrin mRNA was dramatically increased in NCI-H292 cells while the increment was significantly less pronounced in primary HBE cells, among which, the highest increase was observed in DHBE-Asthma cells. It is clear that the differences in pendrin mRNA produced following IL-4 stimulation are not linked to basal pendrin expression levels, since pendrin mRNA expression in un-stimulated cells did not significantly differ between any of the cell types tested. Moreover, it is not related to variable activation of the IL-4 signalling pathway, as the amount of phosphorylated STAT6 following IL-4 exposure was equivalent in the cell types studied.

The basal methylation pattern observed in the different cellular models was generally similar with the particular exception of CpG site 90, which was significantly more methylated in primary HBE cells compared to NCI-H292 cells. Interestingly, we discovered that activation of the IL-4 signalling pathway modifies the epigenetic status of the pendrin promoter. Specifically, IL-4 orchestrates site-specific demethylation of CpG site 90, as well as CpG site 90 bis (created by the g. $-1747 \mathrm{~A}>\mathrm{C}$ (rs2712228) SNP only in primary HBE cells) located 81 nucleotides and 55 nucleotides downstream of the $\mathrm{N}_{4}$ GAS motif, respectively. In line with our observations, IL-4 was recently shown to drive gene-specific demethylation during monocyte differentiation [33].

The epigenetic state of certain CpG sites within the pendrin promoter may explain the differential increase in pendrin mRNA following stimulation with IL-4. There are several lines of evidence supporting cross-talk between transcription factor binding and methylation of CpG sites located within transcription factor consensus binding sequences or in close proximity to them $[34,35]$. CpG site 91 is located only 2 nucleotides downstream of the functional $\mathrm{N}_{4}$ GAS motif - a position that appears to be ideal for controlling the accessibility of transcription factors to this motif. Indeed, it has been already speculated that the methylation status of this CpG site might contribute to IL-4 stimulated changes in pendrin expression [24]. However, the majority of gDNA in all the cell types used in the present study was not methylated at CpG site 91, suggesting that it does not likely account for the observed

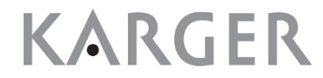


differences in pendrin mRNA expression levels following IL-4 treatment.

Rather, we highlight CpG sites 90 bis and 90 as candidate regulators of pendrin mRNA expression. From the experiments described here, it is evident that at basal conditions the amount of gDNA methylated at CpG site 90 in primary HBE cells was higher compared to the NCI-H292 cells. Moreover, NCI-H292 gDNA does not contain CpG site 90bis and in these cells the increase in pendrin mRNA expression obtained after IL-4 exposure was significantly higher when compared to primary HBE cells. These findings suggest that the basal methylation state of site 90 (and/or site 90bis, if present) might be important for IL-4 induced increases in pendrin mRNA expression. Based on the assumption that low CpG methylation allows transcription, the collected data could indicate that the chromatin structure of NCI-H292 cells is in a permissive state for transcription factor binding in the $\mathrm{N}_{4}$ GAS motif region because of the low basal methylation of CpG site 90 . On the other hand, the chromatin in the primary HBE cells might be in a more closed conformation since most of the gDNA in these cells is methylated at CpG sites 90 and 90bis in the un-stimulated condition. Demethylation of these two CpG sites may be necessary to open the chromatin and allow the binding of STAT6 and/or additional transcription factors that might cooperate with STAT6 [36] to promote pendrin transcription. The demethylation process required in primary HBE cells could therefore delay transcription with respect to NCI-H292 cells, resulting in less production of pendrin mRNA after 48 hrs treatment with IL-4.

The same assumption is in line with the basal methylation state of $\mathrm{CpG}$ site $90 \mathrm{bis}$ and 90 and the magnitude of pendrin mRNA levels following IL-4 exposure among the primary HBE cells. The data showed that the increase in pendrin mRNA in response to IL-4 was significantly higher in DHBE-Asthma cells compared to the NHBE and DHBE-COPD cells, possibly because in basal conditions more of the gDNA from these latter cell types was methylated at CpG sites 90 bis and 90 compared to the DHBE-Asthma cells.

It is interesting that the g.-1747A $>C$ (rs2712228) SNP introducing CpG site 90bis in the primary HBE cell models is present in $94.5 \%$ of Africans and that asthma symptom rates are lower in Africa than in industrialized countries [37]. Whether this SNP might be protective against asthma in the African population requires further investigation.

In conclusion, we have demonstrated that the $\mathrm{T}_{\mathrm{H}} 2$-type cytokine, IL-4, causes site- and cell-specific changes in $\mathrm{CpG}$ methylation of the human pendrin promoter. We propose that the amount of gDNA methylated at CpG sites 90 and 90 bis (when present) may dictate how fast and to what extent the cell responds to IL-4 in terms of pendrin mRNA production.

\section{Acknowledgements}

We sincerely thank Elisabeth Mooslechner for her expert secretarial assistance. Selma M. Soyal was supported by an FWF grant (Elise Richter Project V 344-B24).

\section{Disclosure Statement}

The authors have no conflicts of interest to declare.

\section{References}

1 Scott DA, Wang R, Kreman TM, Sheffield VC, Karniski LP: The Pendred syndrome gene encodes a chlorideiodide transport protein. Nat Genet 1999;21:440-443.

- Soleimani M, Greeley T, Petrovic S, Wang Z, Amlal H, Kopp P, Burnham CE: Pendrin: an apical Cl-/OH-/ HCO3- exchanger in the kidney cortex. Am J Physiol Renal Physiol 2001;280:F356-364. 


\section{Cellular Physiology Cell Physiol Biochem 2017;41:1491-1502 \begin{tabular}{l|l|l} 
and Biochemistry & DOI: 10.1159/000470720 2017 The Author(s). Published by S. Karger AG, Basel \\
www.karger.com/cpb
\end{tabular}

3 Royaux IE, Wall SM, Karniski LP, Everett LA, Suzuki K, Knepper MA, Green ED: Pendrin, encoded by the Pendred syndrome gene, resides in the apical region of renal intercalated cells and mediates bicarbonate secretion. Proc Natl Acad Sci U S A 2001;98:4221-4226.

4 Everett LA, Glaser B, Beck JC, Idol JR, Buchs A, Heyman M, Adawi F, Hazani E, Nassir E, Baxevanis AD, Sheffield VC, Green ED: Pendred syndrome is caused by mutations in a putative sulphate transporter gene (PDS). Nat Genet 1997;17:411-422.

5 Bizhanova A, Kopp P: Genetics and phenomics of Pendred syndrome. Mol Cell Endocrinol 2010;322:83-90.

6 Wangemann P: The role of pendrin in the development of the murine inner ear. Cell Physiol Biochem 2011;28:527-534.

7 Hadchouel J, Busst C, Procino G, Valenti G, Chambrey R, Eladari D: Regulation of extracellular fluid volume and blood pressure by pendrin. Cell Physiol Biochem 2011;28:505-512.

8 Amlal H, Soleimani M: Pendrin as a novel target for diuretic therapy. Cell Physiol Biochem 2011;28:521526.

9 Bidart JM, Lacroix L, Evain-Brion D, Caillou B, Lazar V, Frydman R, Bellet D, Filetti S, Schlumberger M: Expression of Na+/I- symporter and Pendred syndrome genes in trophoblast cells. J Clin Endocrinol Metab 2000;85:4367-4372.

10 Rillema JA, Hill MA: Pendrin transporter carries out iodide uptake into MCF-7 human mammary cancer cells. Exp Biol Med (Maywood) 2003;228:1078-1082.

11 Lacroix L, Mian C, Caillou B, Talbot M, Filetti S, Schlumberger M, Bidart JM: Na(+)/I(-) symporter and Pendred syndrome gene and protein expressions in human extra-thyroidal tissues. Eur J Endocrinol 2001;144:297-302.

12 Suzuki K, Royaux IE, Everett LA, Mori-Aoki A, Suzuki S, Nakamura K, Sakai T, Katoh R, Toda S, Green ED, Kohn LD: Expression of PDS/Pds, the Pendred syndrome gene, in endometrium. J Clin Endocrinol Metab 2002;87:938-941.

13 Pelzl L, Fakhri H, Umbach AT, Gawaz M, Paulmichl M, Lang F: Sgk1 sensitive pendrin expression in murine platelets. Cell Physiol Biochem 2013;32:210-220.

-14 Kuperman DA, Lewis CC, Woodruff PG, Rodriguez MW, Yang YH, Dolganov GM, Fahy JV, Erle DJ: Dissecting asthma using focused transgenic modeling and functional genomics. J Allergy Clin Immunol 2005;116:305311.

15 Nakagami Y, Favoreto S, Jr., Zhen G, Park SW, Nguyenvu LT, Kuperman DA, Dolganov GM, Huang X, Boushey HA, Avila PC, Erle DJ: The epithelial anion transporter pendrin is induced by allergy and rhinovirus infection, regulates airway surface liquid, and increases airway reactivity and inflammation in an asthma model. J Immunol 2008;181:2203-2210.

16 Nakao I, Kanaji S, Ohta S, Matsushita H, Arima K, Yuyama N, Yamaya M, Nakayama K, Kubo H, Watanabe M, Sagara H, Sugiyama K, Tanaka H, Toda S, Hayashi H, Inoue H, Hoshino T, Shiraki A, Inoue M, Suzuki K, Aizawa H, Okinami S, Nagai H, Hasegawa M, Fukuda T, Green ED, Izuhara K: Identification of pendrin as a common mediator for mucus production in bronchial asthma and chronic obstructive pulmonary disease. J Immunol 2008;180:6262-6269.

17 Di Valentin E, Crahay C, Garbacki N, Hennuy B, Gueders M, Noel A, Foidart JM, Grooten J, Colige A, Piette J, Cataldo D: New asthma biomarkers: lessons from murine models of acute and chronic asthma. Am J Physiol Lung Cell Mol Physiol 2009;296:L185-197.

18 Izuhara K, Ohta S, Shiraishi H, Suzuki S, Taniguchi K, Toda S, Tanabe T, Yasuo M, Kubo K, Hoshino T, Aizawa H: The mechanism of mucus production in bronchial asthma. Curr Med Chem 2009;16:2867-2875.

19 Lewis CC, Yang JY, Huang X, Banerjee SK, Blackburn MR, Baluk P, McDonald DM, Blackwell TS, Nagabhushanam V, Peters W, Voehringer D, Erle DJ: Disease-specific gene expression profiling in multiple models of lung disease. Am J Respir Crit Care Med 2008;177:376-387.

20 Pedemonte N, Caci E, Sondo E, Caputo A, Rhoden K, Pfeffer U, Di Candia M, Bandettini R, Ravazzolo R, Zegarra-Moran O, Galietta LJ: Thiocyanate transport in resting and IL-4-stimulated human bronchial epithelial cells: role of pendrin and anion channels. J Immunol 2007;178:5144-5153.

21 Nofziger C, Vezzoli V, Dossena S, Schonherr T, Studnicka J, Nofziger J, Vanoni S, Stephan S, Silva ME, Meyer G, Paulmichl M: STAT6 Links IL-4/IL-13 Stimulation With Pendrin Expression in Asthma and Chronic Obstructive Pulmonary Disease. Clin Pharmacol Ther 2011;90:399-405.

22 Nofziger C, Dossena S, Suzuki S, Izuhara K, Paulmichl M: Pendrin function in airway epithelia. Cell Physiol Biochem 2011;28:571-578. 


\section{Cellular Physiology Cell Physiol Biochem 2017;41:1491-1502 \begin{tabular}{cc|c|c|}
\cline { 2 - 3 } aOI: 10.1159/000470720 & $\begin{array}{l}\text { O } 2017 \text { The Author(s). Published by S. Karger AG, Basel } \\
\text { www.karger.com/cpb }\end{array}$
\end{tabular}

23 Vanoni S, Nofziger C, Dossena S, Soyal SM, Patsch W, Plevani P, Duschl A, Paulmichl M: The human pendrin promoter contains two N(4) GAS motifs with different functional relevance. Cell Physiol Biochem 2013;32:238-248.

24 Lee A, Nofziger C, Dossena S, Vanoni S, Diasio R, Paulmichl M: Methylation of the human pendrin promoter. Cell Physiol Biochem 2011;28:397-406.

-25 Lewis JD, Meehan RR, Henzel WJ, Maurer-Fogy I, Jeppesen P, Klein F, Bird A: Purification, sequence, and cellular localization of a novel chromosomal protein that binds to methylated DNA. Cell 1992;69:905-914.

-26 Robertson KD, Wolffe AP: DNA methylation in health and disease. Nat Rev Genet 2000;1:11-19.

-27 Kaludov NK, Wolffe AP: MeCP2 driven transcriptional repression in vitro: selectivity for methylated DNA, action at a distance and contacts with the basal transcription machinery. Nucleic Acids Res 2000;28:19211928.

28 Jost JP, Hofsteenge J: The repressor MDBP-2 is a member of the histone H1 family that binds preferentially in vitro and in vivo to methylated nonspecific DNA sequences. Proc Natl Acad Sci U S A 1992;89:94999503.

29 Nan X, Ng HH, Johnson CA, Laherty CD, Turner BM, Eisenman RN, Bird A: Transcriptional repression by the methyl-CpG-binding protein MeCP2 involves a histone deacetylase complex. Nature 1998;393:386-389.

-30 Jones PL, Veenstra GJ, Wade PA, Vermaak D, Kass SU, Landsberger N, Strouboulis J, Wolffe AP: Methylated DNA and MeCP2 recruit histone deacetylase to repress transcription. Nat Genet 1998;19:187-191.

-31 Livak KJ, Schmittgen TD: Analysis of relative gene expression data using real-time quantitative PCR and the 2(-Delta Delta C(T)) Method. Methods 2001;25:402-408.

-32 Moskalev EA, Zavgorodnij MG, Majorova SP, Vorobjev IA, Jandaghi P, Bure IV, Hoheisel JD: Correction of PCR-bias in quantitative DNA methylation studies by means of cubic polynomial regression. Nucleic Acids Res 2011;39:e77.

-33 Vento-Tormo R, Company C, Rodriguez-Ubreva J, de la Rica L, Urquiza JM, Javierre BM, Sabarinathan R, Luque A, Esteller M, Aran JM, Alvarez-Errico D, Ballestar E: IL-4 orchestrates STAT6-mediated DNA demethylation leading to dendritic cell differentiation. Genome Biol 2016;17:4.

34 Blattler A, Farnham PJ: Cross-talk between site-specific transcription factors and DNA methylation states. J Biol Chem 2013;288:34287-34294.

35 Medvedeva YA, Khamis AM, Kulakovskiy IV, Ba-Alawi W, Bhuyan MS, Kawaji H, Lassmann T, Harbers M, Forrest AR, Bajic VB, consortium F: Effects of cytosine methylation on transcription factor binding sites. BMC Genomics 2014;15:119.

36 Goenka S, Kaplan MH: Transcriptional regulation by STAT6. Immunol Res 2011;50:87-96.

37 Wjst M, Boakye D: Asthma in Africa. PLoS Med 2007;4:e72. 